\title{
Comunidades virtuais: construindo o conhecimento através da interação
}

\author{
Rute Vera Maria Favero \\ Escola Técnica - Universidade Federal do Rio Grande do Sul (UFRGS) \\ Rua Ramiro Barcelos, 2777 - Santana \\ 900035-007- Porto Alegre - RS - Brasil \\ rutevera@escolatecnica.ufrgs.br \\ Liane Margarida Rockenbach Tarouco \\ CINTED - Universidade Federal do Rio Grande do Sul (UFRGS) \\ Av. Paulo Gama, 110 - prédio 12105 - 3 andar \\ CEP 90040-060 - Porto Alegre - RS - Brasil \\ liane@penta3.ufrgs.br
}

Resumo: Este artigo mostra que é possível a construção do conhecimento em comunidades virtuais, a partir do momento em que os sujeitos que fazem parte dessas comunidades passam a manter interações dialógicas. Aborda também a importância do diálogo no processo da aprendizagem; diálogo, esse, visto sob as perspectivas freireana e piagetiana. Além disso, são analisadas estratégias que permitem conseguir uma melhor interação e uma maior colaboração entre os sujeitos. A observação realizada em cursos a distância, oferecidos em ambientes virtuais de aprendizagem, permitiu verificar que ocorre a construção do conhecimento quando o aluno interage nas comunidades virtuais, utilizando as ferramentas específicas para isso, como chat, fórum, e-mail entre outros. Os resultados encontrados apontam para a necessidade de estratégias de interação dialógicas a serem utilizadas pelos mediadores que atuarão em cursos a distância, a fim de incentivar e estimular os educandos para que realizem formas diversas de interação, com os outros atores do curso, que possibilitem passar de um nível de conhecimento menor para um outro maior.

Palavras-chave: interação, comunidades virtuais, geração de conhecimento, diálogo, ambiente virtual de aprendizagem

Abstract: This article sample that is possible the construction of the knowledge in virtual communities, from the moment where the students that are part of these communities start to keep interactions that make possible the dialogue. It also approaches the importance of the dialogue in the process of the learning; dialogue based on the studies developed by Paulo Freire and Jean Piaget. Moreover, strategies are analyzed that allow to obtain one better interaction and a bigger cooperation between the people. The observation accomplished in courses in the distance, offered in a learning virtual environment, allowed to verify that the construction of the knowledge occurs when the student interacts in the virtual communities, using the specific tools for this, as chat, fórum, email among others. The results of this research points out the importance of interaction strategies that make possible the dialogue to be used for the mediators taht will act in the distance courses, in order to stimulate the students so that they carry through diverse forms of interaction, with the other actors of the course, that make possible to pass of a level of smaller knowledge for one another greater.

Key-words: interaction, virtual communities, knowledge construction, dialogue, learning virtual environment v. 6 № 1 , Julho, 2008 


\section{Introdução}

Este artigo tem como objetivo mostrar que é possível a geração de conhecimento em comunidades virtuais, dentre essas os Ambientes Virtuais de Aprendizagem (AVA), a partir das interações mantidas entre os atores desses ambientes.

Quando um educando mantém uma interação dialógica com seus colegas ou com seus professores ou tutores há a aquisição mútua de conhecimento. Partindo-se do princípio que diálogo não é permuta ou simples troca, mas sim uma revelação dos interlocutores, o diálogo que ocorre entre os educadores e educandos e entre educandos e educadores, num ambiente virtual de aprendizagem, é essencial e pode contribuir para uma maior geração de conhecimento.

$\mathrm{O}$ ato de ensino e aprendizagem constitui principalmente um ato de comunicação e essa comunicação, sendo a distância, pode se dar de forma mediatizada, isto é, utilizando o computador e as mídias existentes, constituindo assim um dos principais campos de formação a distância. As formas de comunicação que permitem um diálogo são muito variadas e realizam-se através da linguagem, que tem como função primária a comunicação e o intercâmbio social (LANE, 2001), nas comunidades virtuais.

Para uma melhor compreensão do assunto, inicialmente será definido o que são comunidades virtuais.

\section{Comunidades virtuais}

Um número crescente de pessoas passou a se comunicar virtualmente e participam de atividades que ocorrem no espaço virtual de comunicação e informação denominado ciberespaço, um termo cunhado por Gibson, em seu livro Neuromancer, que o definia como sendo "um lugar onde se vai com a mente, catapultada pela tecnologia, enquanto o corpo fica para trás".

O ciberespaço representa o mais recente desenvolvimento da evolução da linguagem, segundo Levy, onde

os signos são adquiridos, por intermédio do software, dessa escrita tornada viva: uma potência da ação autônoma de um ambiente numérico que lhe é próprio. O ciberespaço torna-se o sistema ecológico do mundo das idéias, uma noosfera abundante, em transformação acelerada, que começa a tomar o controle do conjunto da biosfera e a dirigir sua evolução a seus próprios fins. A vida em sua completude eleva-se em direção ao virtual, ao infinito, pela porta da linguagem humana (Levy, Apud LEMOS in Apresentação, 2002, p. 14).

Para Lemos,

O ciberespaço é um ambiente mediático, como uma incubadora de ferramentas de comunicação, (...) conectando pontos ordinários, criando territorialização e desterritorialização sucessivas. (...) formando comunidades ordinárias. É um espaço (relacional) de comunhão, colocando em contato, através do uso de técnicas de comutação eletrônica, pessoas do mundo todo. (...) Mais do que um fenômeno técnico, o ciberespaço é um fenômeno social (LEMOS, 2002, p. 146, 148). 
3

E é esse fenômeno social que permite formar redes de máquinas e pessoas que se comunicam, formando uma matrix da vida real, potencializada na vida virtual, através das comunidades virtuais que surgem, possibilitando a construção social do conhecimento, mediada por computadores.

Para Moore (2007, p. 247), o aprendizado em colaboração, com base no grupo, capacita o desenvolvimento de comunidades de aprendizado e, apesar da comunicação a distância ser veiculada por um meio artificial, a necessidade de uma "presença social" tem se mostrado muito importante na construção dessas redes que possibilitam a construção do conhecimento. Em um estudo realizado sobre a instrução mediada por computador, Cheng (Apud MOORE, 2007, p. 247) verificou que os alunos que trabalharam em colaboração com seus colegas atingiram um índice de conclusão de $90 \%$, contra $22 \%$ dos que trabalharam individualmente.

A dinâmica do grupo virtual atraía todos os participantes na direção de várias formas de conciliação e discussão visando construir em um contexto social um conhecimento comumente aceitável e o apreço, a inclusão e o senso de solidariedade do grupo, a facilidade de expressão e a síntese de vários pontos de vista, sem que um único aluno se destaque, são características importantes nessa construção social on-line bem-sucedida do conhecimento (MOORE, 2007, p. 247).

A importância das relações sociais que ocorrem na virtualidade e das sensações e emoções que perpassam essas relações mostram que não é somente a tecnologia, a máquina que está por trás disso, mas também um ser humano que busca interagir e se completar através das relações que surgem nas comunidades virtuais, consideradas "agregações virtuais que emergem da Rede quando um conjunto de pessoas se engaja em discussões públicas por um certo tempo e com emoções suficientes para formar teias de relações pessoais no ciberespaço"(RHEINGOLD, 2000).

Comunidade virtual não é apenas um espaço tecnológico que permite uma comunicação mais abrangente e globalizada, mas sim um espaço onde as pessoas colaboram entre si, e que permite a autonomia dos educandos e a construção de trabalhos coletivos, possibilitando a geração de conhecimento; é um espaço social de comunicação, que possibilita a ocorrência do diálogo.

E o que é diálogo?

\section{O Diálogo}

Para Paulo Freire, o diálogo é condição essencial para a formação da consciência crítica e é construído na relação "entre sujeitos mediatizados pelo mundo". A teoria freireana foi utilizada como auxilio para entender o que é diálogo.

O diálogo é um processo coletivo e pode ocorrer na forma presencial, ou online, em comunidades virtuais. Quando ocorre em ambientes virtuais, usa uma linguagem específica através dos textos escritos. A comunicação se dá utilizando recursos associados à internet - e-mail, chat, fórum, diário, entre outros, meios que permitem se comunicar com várias pessoas ao mesmo tempo e num espaço de tempo bem mais curto. A comunicação dá sentido a vida das pessoas.

Mas, se a comunicação e a informação ocorrem ao nível da vida sobre o suporte, imaginemos sua importância e, portanto, a da dialogicidade, na existência humana no mundo. Nesse nível, a comunicação e a informação se servem de sofisticadas linguagens e de instrumentos tecnológicos que 
4

"encurtam" o espaço e o tempo. A produção social da linguagem e de instrumentos com que os seres humanos melhor interferem no mundo anuncia o que será a tecnologia (FREIRE, 2004, p.74-75).

Os diálogos entre as pessoas devem estar recheados de "conteúdos significativos", para não ser uma "mera conversa". Dialogar não seria uma mera ação "verbalista", utilizando um termo usado por Paulo Freire, mas sim uma conversa que gera conhecimento para todas as pessoas que estejam envolvidas neste dialogar. "A palavra conversar vem da união de duas raízes latinas: cum que quer dizer "com", e versare que quer dizer "dar voltas com" o outro. (...) O que ocorre no "dar voltas juntos" dos que conversam, e o que acontece aí com as emoções, a linguagem e a razão?" (MATURANA, 2001, p.167).

É importante salientar que, um diálogo desenvolvido dentro de um ambiente virtual ocorre totalmente através de textos escritos, portanto, tanto educador quanto educando devem colocar, nesses textos, o máximo de sua intenção e afeto. Um educador deve promover o afeto entre os educandos e dele para os educandos. Conforme muito bem coloca Rubens Alves "toda a experiência de aprendizagem se inicia com uma experiência afetiva. É a fome que põe em funcionamento o aparelho pensador. Fome é afeto. O pensamento nasce do afeto, nasce da fome. Não confundir afeto com beijinhos e carinhos. Afeto, do latim affecare, quer dizer "ir atrás". O afeto é o movimento da alma na busca do objeto de sua fome". (ALVES, 2004, p.52). A interação, feita desta forma, permitirá que educandos e educadores modifiquem a si próprios, assimilando e sedimentando novos conhecimentos.

Para entender o diálogo e para entender os processos de aprendizagem coletiva, buscou-se aporte na teoria piagetiana, com o intuito de dar uma conotação cognitiva à abordagem de Paulo Freire.

Para Piaget, a aprendizagem se dá a partir da assimilação e acomodação e pode gerar a equilibração, para depois ocorrer um novo desequilíbrio, onde tudo se inicia novamente. Para que isso ocorra é necessário que o sujeito interaja com o objeto e com os outros sujeitos de seu conhecimento. $\mathrm{Na}$ interação entre estes, se constrói o conhecimento.

Além dos fatores orgânicos, que condicionam do interior os mecanismos da ação, toda conduta supõe, com efeito, duas espécies de interações que a modificam de fora e são indissociáveis uma da outra: a interação entre o sujeito e os objetos e a interação entre o sujeito e os outros sujeitos (...) cada interação entre sujeitos individuais modificará os sujeitos uns em relação aos outros (PIAGET, 1973, p.34, 35).

Com base nessas concepções, pôde-se estabelecer categorias que permitissem reconhecer a ocorrência de diálogo, nos ambientes virtuais. As categorias Cooperação, Eqüidade na relação, Geração de conhecimento, Incentivo e Participação contínua são consideradas indicadores de diálogo, segundo Paulo Freire e Piaget.

Para Paulo Freire, ocorre cooperação entre os interlocutores, quando os envolvidos passam a se ajudar mutuamente, objetivando um fim comum, portanto, sempre que se identificar que os sujeitos estão se ajudando e colaborando entre si, e ajudando e colaborando com o grupo como um todo, isto é, estejam auxiliando os colegas em suas dúvidas, ou expondo suas idéias e estas servirem para construir um conhecimento coletivo, considera-se que estes sujeitos podem estar envolvidos no que definimos como sendo diálogo, desde que estejam ocorrendo, simultaneamente, também as outras categorias.

V. 6 № 1, Julho, 2008 


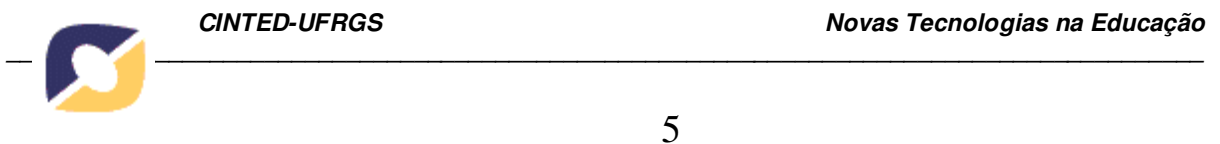

Enquanto educandos e educadores "co-operarem" entre si possibilitarão o surgimento de diálogos que permitem novas construções. "Chamamos cooperação toda a relação entre dois ou $\mathrm{n}$ indivíduos iguais ou acreditando-se como tal, dito de outro modo, toda relação social na qual não intervém qualquer elemento de autoridade ou de prestígio" (PIAGET apud MONTANGERO \& MAURICE-NAVILLE, 1998, p.120121).

Eqüidade na relação são identificadas nas interações que ocorrem quando os sujeitos se envolvem numa relação de respeito mútuo com deveres e obrigações de um lado e direitos, compensações e retribuição de outro, mantendo uma horizontalidade na relação. Ao procurarem dialogar, as pessoas se revelam e se abrem para receber e dar bem mais do que simples informações. "Nesse sentido, a comunicação é vida e fator de mais-vida. Mas, se a comunicação e a informação ocorrem ao nível da vida sobre o suporte, imaginemos sua importância e, portanto, a da dialogicidade, na existência humana no mundo" (FREIRE, 2004, p.74). E diz ainda que diálogo não é dominação, que não há diálogo se não houver humildade e que a "dialogicidade é cheia de curiosidade, de inquietação. De respeito mútuo entre os sujeitos que dialogam" (idem, p.80). O sujeito sozinho permanece egocêntrico, mas numa comunicação dialógica não pode haver egocentrismo e tampouco relações de coação. Deve, isso sim, haver um equilíbrio nas trocas.

É claro, com efeito, que sem uma disciplina assegurando a coordenação dos pontos de vista por meio de uma regra de reciprocidade, a "livre troca" fracassa continuamente, seja devido ao egocentrismo (individual, nacional ou resultante da polarização da sociedade em classes sociais), seja devido às coações (devidas às lutas entre tais classes, etc) (PIAGET, 1973, p.110).

Entende-se por geração de conhecimento sempre que, numa ordem temporal, aparecer um nível de explicitação sobre um determinado tema e depois isso passar a aparecer numa estruturação mais complexa, permitindo reconhecer que o educando conseguiu um melhor entendimento do que estava sendo exposto durante o curso ou quando, por depoimento, o aluno admitir que aconteceu conhecimento, devido à colaboração dos outros. Para Paulo Freire dialogar significa manter uma conversa que gera conhecimento para todas as pessoas que estejam envolvidas. E mais "promovendo a percepção da percepção anterior e o conhecimento do conhecimento anterior, a descodificação, desta forma, promove o surgimento de nova percepção e 0 desenvolvimento de novo conhecimento" (2003, p.110). E acrescenta ainda "a relação dialógica - comunicação e intercomunicação entre sujeitos, refratários à burocratização de sua mente, abertos à possibilidade de conhecer e de mais conhecer é indispensável ao conhecimento" (2004, p.80).

\section{Conforme Piaget}

A impressão afetiva nada mais é que a consciência de uma necessidade ou de um interesse capaz de levar o organismo a se mobilizar para satisfazê-la e, assim, atingir o equilíbrio. Explicando melhor, a afetividade representa a fonte energética que mobiliza a inteligência, sem alterá-la, da mesma forma que o combustível de um carro provoca o funcionamento do motor sem modificar a máquina" (PIAGET apud FARIA, 1995, p.10).

Incentivo é considerado sempre que ocorrer, seja através de colegas, seja através dos professores, o ato de incentivar, onde os interlocutores (educandos e educadores) incentivam seus colegas ou alunos a continuarem a participar do curso, interagindo e realizando as tarefas solicitadas no mesmo, indicando-lhes a importância 
6

da participação e continuidade dos mesmos para o sucesso de todo o processo. $\mathrm{O}$ incentivo pode ser feito, também, através de convites para participar dos grupos criados, com a finalidade de realizar determinadas tarefas que são solicitadas ou a participarem mais ativamente dos fóruns com a intenção de tornar a discussão mais interessante. Este incentivo pode ser feito através de e-mails, diretamente a um educando, ou a um grupo deles. Pode, também, ser feito durante um chat pelo educador ou, até, pelos próprios educandos.

A participação contínua é observada levando-se em conta a contigüidade de interações que podem ser efetuadas pelos alunos durante a realização do curso, considerando-se a participação desde o inicio ao fim do mesmo, mas sempre se observando se o educando participa constantemente e, preferencialmente, em todas as ferramentas ofertadas, independente do tipo de interação que ocorra.

Essas categorias de diálogo advém de uma pesquisa* realizada em comunidades virtuais e em ambientes virtuais de aprendizagem.

\section{A pesquisa}

Para verificar a ocorrência de diálogo em comunidades virtuais e a sua influência no processo de aprendizagem foi realizada uma pesquisa, onde foram analisados vários AVA (Moodle, Teleduc, AMEM) e comunidades virtuais (Orkut, Mell, comunidades desenvolvidas em empresas como o SEBRAE e outras), dos quais participaram alunos de cursos diversos, porém, a análise efetiva foi realizada num curso a distância, oferecido através do Ambiente Teleduc, em que são oferecidas diversas ferramentas que permitem uma maior interação, observando-se as trocas ocorridas entre os atores dos cursos.

Foi feito um Estudo de Caso, a fim de se alcançar maior compreensão do caso pesquisado e permitir escolher um foco mais preciso para averiguação dos dados coletados. Foram empregadas as abordagens qualitativa e quantitativa uma vez que os dados seriam analisados através de categorias e, portanto, requeria um grande volume de dados. Todos os dados foram organizados em tabelas permitindo uma ordenação lógica dos mesmos e uma melhor visualização do todo. Sempre que, nas interações, foram percebidas ocorrências de diálogo, estas foram separadas para análise posterior, onde as mesmas seriam avaliadas segundo as categorias que foram estabelecidas a partir da revisão teórica realizada.

No curso pesquisado, 36 alunos tiveram participação ativa no ambiente, isto é, participaram enviando e respondendo e-mails, respondendo aos fóruns, postando no mural, diário de bordo e portfólio. Os dados coletados para a análise advieram das interações realizadas entre os participantes, durante o período do curso e a coleta teve como base a revisão teórica realizada, considerando-se quando ocorriam diálogos, levando-se em conta a concepção de diálogo pregada por Paulo Freire e Jean Piaget.

Nessa pesquisa, pôde-se verificar que, quando um AVA permite interações entre os próprios educandos e entre educandos e educadores, é possível que ocorra o diálogo entre esses sujeitos. $\mathrm{O}$ ambiente estudado permitia interações, através de vários recursos como, fóruns, chats, e-mails, diários de bordo e mural. Percebeu-se, também, que pode existir diálogo ao se utilizar qualquer ferramenta oferecida pelo ambiente. Desde que os alunos sejam instigados, eles respondem ativamente e passam a participar efetivamente, cooperando com os colegas, incentivando-os e, também, desenvolvendo-se intelectualmente. Ao se sentirem parte do processo, ao perceberem que não estão V. 6 № 1, Julho, 2008 
7

sozinhos e ao perceberem que estão adquirindo aprendizagem, os educandos se motivam e permanecem fazendo parte ativamente desse processo até o final.

A pesquisa mostrou que, dentre os alunos que tiveram participação ativa no ambiente, isto é, participaram enviando e respondendo e-mails, respondendo aos fóruns, postando no mural, diário de bordo e portfólio, portanto mantiveram interações dialógicas, $81 \%$ foram os que obtiveram um crescimento na sua aprendizagem.

Nesse enfoque, a função do professor/tutor é propiciar situações que permitam a interação entre ele e os educandos e entre os educandos, pois a interação social favorece a aprendizagem. Da mesma forma que para Freire, para Piaget um sujeito não aprende sozinho, mas sim, somente a partir do momento que aprende a agir cooperativamente, na relação com o outro, onde estes podem dialogar na busca de um novo conhecer, fortalecendo as trocas que ocorrem.

A interação permitirá que alunos e professores se modifiquem mutuamente, assimilando e sedimentando novos conhecimentos, a partir dos conhecimentos anteriormente estruturados e internalizados.

A partir desses conceitos, pode-se perceber que um professor/tutor deve estabelecer estratégias de interação e quando for dialogar com seus alunos, é interessante que leve em conta qual o nível de conhecimento deles, isto é, precisa estar aberto para o saber dos alunos e ter sensibilidade para reconhecer nesse diálogo qual é o nível de conhecimento deles e, sendo esse diálogo promovido a distância, em um ambiente virtual de aprendizagem, é necessário que o professor (educador) encontre, nesse diálogo, alguma forma que permita a ele conhecer melhor os seus alunos. "Para ser válida, toda educação, toda ação educativa deve necessariamente estar precedida de uma reflexão sobre o homem e de uma análise do meio de vida concreto a quem queremos educar (ou melhor dito: a quem queremos ajudar a educar-se)" (FREIRE, 1980, p.34).

\section{Estratégias de interação}

A tecnologia mudou a maneira como as relações sociais se apresentam, mas, para compreender as mudanças, é importante perceber que as relações sociais em si continuam essencialmente iguais definindo padrões de comportamentos de liderança, de decisão, de competição, de conflitos, de estruturas de trabalho e cooperação (ARONSON, E., WILSON, T.D e AKERT, R.M, 2002).

Formar relacionamentos com outras pessoas atende a muitas necessidades humanas básicas, e a internet estabeleceu novos paradigmas quanto às relações sociais. A era da informação trouxe mudanças na maneira da sociedade se comunicar, onde a comunicação ocorre de forma mais ágil, independente da localização geográfica ou de qualquer barreira espacial ou temporal. Assim, as pessoas buscam se reunir em grupos sociais, visando compartilhar interesses comuns.

Nos grupos sociais que se formam através das redes de computadores, nas comunidades virtuais, estabelecem-se mais do que simples relações homem-máquina, ou relações homem-homem que buscam apenas trocas "mecânicas" de conhecimento, ou solucionar problemas e tomar decisões. Muitos sentimentos e sensações perpassam essas relações, surgindo relações emocionais e subjetivas.

É importante que a infra-estrutura tecnológica que envolve essas redes de computadores funcione corretamente e que os educandos e professor/tutores conheçam V. 6 № 1 , Julho, 2008 
como funcionam esses ambientes virtuais para que seja possível ocorrer interações entre eles, mas isso só poderá ocorrer se existir um interesse em compartilhar descobertas e saberes e se houver uma compreensão de que ocorre um fortalecimento das relações através das interações, promovendo encontros que não aconteceriam se dependessem de oportunidades de se encontrarem pessoalmente.

Acima de tudo, torna-se mister a adoção de estratégias para promover uma melhor interação e uma maior colaboração entre os atores desse processo e para que os mesmos permaneçam a fïm de se sentirem integrados à comunidade virtual, criando laços sociais mais perenes.

Esses laços ocorrem nos grupos sociais que surgem nos ambientes virtuais e são definidos como a reunião de duas ou mais pessoas que interagem entre si e são interdependentes, no sentido de que suas necessidades e seus objetivos levam-nas a depender umas das outras (CARTWRIGHT, ZANDER, 1968; LEWIN, 1948, apud ARONSON et al, 2002, p.196).

A necessidade de pertencer a um grupo é inata e existe em todas as sociedades, pois quando as pessoas estão em grupo são mais do que observadoras passivas umas das outras - elas se socializam, se misturam, se tornam íntimas, e discutem umas com as outras, isto é, interagem. Existe uma tendência de formar grupos homogêneos, isto é, grupos que compartilham suas atitudes, crenças, opiniões e que são regidos por normas próprias. Percebe-se isso, nas discussões que ocorrem nos fóruns, por exemplo, onde os alunos participam das discussões e respondem mais ativamente quando o assunto condiz com suas idéias, com seus conhecimentos e quando quem iniciou a discussão faz parte do "seu grupo", que pode ser alguém da mesma cidade, da mesma universidade.

Entre os membros de um grupo, faz-se necessária a existência de papéis que definam como cada pessoa deve se comportar, sendo que papéis bem definidos tendem a deixar as pessoas mais satisfeitas e a obterem bom desempenho (BASTIEN, HOSTAGER, 1988; BARLEY, BECHKY, 1994, apud ARONSON, et al, 2002, p. 203).

Um dos mais importantes papéis num grupo é o do líder. Dele depende o sucesso ou o fracasso de um grupo. Um bom líder não é definido, necessariamente, pelas suas características pessoais, mas é necessário que ele seja a "pessoa certa, no momento certo, na situação certa". Segundo Aronson (2002, p. 205), existem dois tipos de líderes: o orientado para a tarefa, que se preocupa mais em conseguir que o trabalho seja feito e o orientado para o relacionamento que se preocupa mais com os sentimentos e os relacionamentos dos membros do grupo. O sucesso do líder dependerá da natureza da situação. Num AVA o líder deve ser o professor/tutor que deverá saber o momento para assumir um tipo ou outro de liderança.

Uma situação a ser observada em ambientes virtuais é a quantidade de pessoas que existem, pois se houver muitas pessoas, não será possível interagir com todas, então o professor/tutor de um AVA poderá dividir a quantidade de pessoas que deverão participar de um chat, ou de uma videoconferência, por exemplo.

Muitas são as estratégias que podem ser adotadas por um professor/tutor, em cursos a distância, onde existem grupos sociais, a fim de que o desempenho do grupo seja o mais alto possível. Uma das estratégias que podem ser usadas para isso é o de promover a interação entre os alunos e entre os alunos e ele próprio.

Uma ferramenta disponibilizada na maioria dos AVA é o fórum, muito utilizada no processo de ensino e aprendizagem e permite que ocorra interação entre os 
9

participantes do ambiente virtual, porém não gerenciar um fórum é como sair de uma sala de aula, deixando os alunos numa situação de completo abandono.

Para evitar que os alunos abandonem a discussão e para incentivá-los a participarem, existem algumas precauções que poderão ser tomadas a este respeito, pelo professor/tutor:

- É importante combinar, desde o início, quantas vezes por semana o professor/tutor irá acessar o fórum. Os alunos devem ter bem clara a idéia de que estão lidando com uma ferramenta assíncrona e que, sendo assim, as respostas não serão imediatas.

- É bom conversar com os alunos, logo de início, sobre como eles deverão se portar no ambiente e nas discussões. Deve-se conscientizá-los que, embora não estejam vendo os seus interlocutores, eles existem e poderão ficar ofendidos se o aluno ultrapassar certos limites da etiqueta. Uma sugestão é que se disponibilize a eles um manual falando sobre a netiqueta, dando dicas de comportamento on-line.

- Se um fórum ficar muito longo, este poderá ser arquivado para facilitar a leitura das discussões.

- Lembrar que discussões moderadas e bem desenvolvidas poderão ser muito mais proveitosas do que apenas um conteúdo estático.

- Estabelecer um tempo para que os alunos possam refletir sobre as questões antes de fazer novas postagens.

- Deve haver critérios de avaliação, onde estejam bem claros os objetivos das discussões. Os alunos devem perceber a participação do professor/tutor nas discussões e este deverá fazê-los sentir que as suas postagens são sempre valorizadas. Feedbacks são ótimos aliados nesse processo.

- Pode-se buscar especialistas em um determinado assunto para o fórum de discussão. Poderá ser criado um fórum somente para as questões que lhes serão apresentadas. Deverá ser dado um nome de usuário e uma senha aos especialistas para que possam entrar no fórum nos horários que lhes convierem. Se o número de questões for muito elevado, os próprios alunos poderão votar as melhores para que estas sejam de fato apresentadas.

- Procurar promover debates entre os alunos com diferentes pontos de vista para fomentar as discussões.

- Por surgirem muitas questões administrativas durante as discussões, sugere-se a criação de um fórum apenas para isso. Também pode ser criado um fórum geral com perguntas freqüentes para que não seja necessário repetir determinadas respostas indefinidamente.

- Se o grupo for muito grande, pode-se dividi-lo em mais grupos e então pedir aos alunos que leiam a discussão de determinados grupos e elaborem questões para que seus integrantes respondam. Essa estratégia permite a quem não participou da discussão num primeiro momento, não apenas leia o diálogo, mas reflita sobre as questões levantadas.

- Como a interação entre os alunos se da somente virtualmente, fica faltando, às vezes, aquele laço pessoal que é desenvolvido em aulas presenciais. Para transpor essa barreira, é interessante disponibilizar um fórum social, onde os alunos falem sobre si e discutam assuntos que não estejam relacionados com o tema das aulas. Crie um fórum e incentive os alunos a se apresentarem e a comentarem as apresentações dos demais colegas para dar inicio a esse processo de socialização. 
10

Para estimular o debate podem ser adotadas perguntas que auxiliam no processo da aprendizagem, e um método a ser adotado é o Socratic questioning, lembrando que é preciso ouvir com atenção o interlocutor para avaliar e compor as frases em modo construtivo e, preferivelmente, não antagônico. Podem ser feitas perguntas como: perguntas de esclarecimento, perguntas que verificam suposições, perguntas que verificam evidências e linhas de raciocínio, perguntas sobre pontos de vista ou perspectivas e perguntas que verificam implicações e conseqüências.

Essas precauções auxiliam no processo de ensino e aprendizagem e permitem uma maior interação entre os próprios alunos, como tem sido observado em diversos cursos a distância, onde uma mediação mais clara e intensiva tem estimulado os alunos a participarem mais e a instigarem seus próprios colegas para que participem ativamente. Essas observações continuam acontecendo em cursos na modalidade a distância, nos quais as autoras atuam, a fim de subsidiar novas pesquisas.

\section{Considerações Finais}

A internet torna mais fácil compartilhar materiais de curso, opiniões, conhecimentos e permitem uma maior interação entre os sujeitos. O modo como a mídia é usada se torna mais importante que as tecnologias especificas que são selecionadas.

Sabe-se que, num ambiente Virtual de Aprendizagem, podem ocorrer interações entre os próprios educandos e entre educandos e educadores. Quando um AVA permite estas interações é possível que ocorra o diálogo entre estes sujeitos. Desde que os alunos sejam instigados, eles respondem ativamente e passam a participar efetivamente, cooperando com os colegas, incentivando-os e, também, desenvolvendo-se intelectualmente. Ao se sentirem parte do processo, ao perceberem que não estão sozinhos e ao perceberem que estão adquirindo aprendizagem, os alunos permanecem fazendo parte deste processo até o final. Eles se motivam e continuam participando ativamente, interagindo no ambiente.

Nessa interação é possível demonstrar afetividade e é possível demonstrá-la nos textos que são escritos (ou poderia se dizer falados, pois muito do que é postado num AVA, ou em comunidades virtuais é a fala em forma de texto escrito). Tudo depende da forma como as coisas são ditas. Pode-se expressar sentimentos diversos, no uso dos emoticons, por exemplo. E o que poderia ser dito dos caracteres que vem sendo usados durante a escrita, principalmente em fóruns, chats, como é o caso do uso das reticências (...), dos vários pontos de interrogação (?), ou de exclamação (!), ou ainda dos símbolos (=) indicando um sentimento (na falta de um emoticom)? Parece que as pessoas sentiram a necessidade de uma comunicação mais próxima, mais pessoal, mais humana, mesmo no mundo virtual. Assim a distância percebida pelo sujeito que está interagindo, não é a geográfica; é a de si próprio em relação ao monitor do seu computador.

O aluno será o responsável pela construção do seu próprio conhecimento, portanto se as interações mantidas nos AVA forem interações dialógicas, é possível estabelecer que o conhecimento adquirido por ele passou de um nível menor para um maior.

\footnotetext{
* Pesquisa realizada durante o Mestrado, originando a dissertação de Mestrado defendida em 04/01/2006, intitulada Dialogar ou evadir: Eis a questão!: Um estudo sobre a permanência e a evasão na Educação a Distância, na Universidade Federal do Rio Grande do Sul
} 


\section{Referências Bibliográficas}

ALAVA, Séraphin. Ciberespaço e formações abertas, Porto Alegre: ARTMED, 2002.

ALVES, R. Ao professor, com o meu carinho, Campinas: Verus, $4^{\text {a }}$ edição, 2004.

ARONSON, E.; WILSON,T.D.; AKERT R. M. Psicologia Social. Rio de Janeiro: LTC, 3a. edição, 2002.

Aspectos comportamentais da aprendizagem e trabalho em equipe. Disponível em: http://bpwbrasilia-df.org.br/midias/ Acesso em 01 jun. 2008.

CARVALHO, Maira Brandão. Comunidades Virtuais. Disponível em: http://bpwbrasilia-df.org.br/midias/ Acesso em 01 jun. 2008.

Comunidades Virtuais e novas maneiras de aprender e ensinar. Disponível em: http://bpwbrasilia-df.org.br/midias/ Acesso em 01 jun. 2008.

FARIA, Anália Rodrigues. Desenvolvimento da criança e do adolescente segundo Piaget. $3^{a}$ edição. São Paulo: Ática, 1995.

FAVERO, Rute V. M. Dialogar ou evadir: Eis a questão!: Um estudo sobre a permanência e a evasão na Educação a Distância, no Estado do Rio Grande do Sul. 2006. Porto Alegre: UFRGS, 2006. 169 p. Dissertação de Mestrado.

FREIRE, P. À sombra desta mangueira, São Paulo: Olho D'Água, 4ª edição, 2004.

FREIRE, P. Conscientização: teoria e pratica da libertação: uma introdução ao pensamento de Paulo Freire, São Paulo: Moraes, 1980.

FREIRE, P. Pedagogia do Oprimido, São Paulo: Paz e Terra, 36ª edição, 2003.

GIBSON, William. Neuromancer, São Paulo: Aleph, $3^{\text {a }}$ edição, 2003.

LANE, Silvia T. M. Linguagem, pensamento e representações sociais. In: CODO, Wanderley et al. Psicologia Social: o homem em movimento. São Paulo: Brasiliense, $3^{\text {a }}$ edição, 2001. p. 33.

LEMOS, André. Cibercultura: tecnologia e vida social na cultura contemporânea. Porto Alegre: Sulina, 2002

MATURANA, Humberto R.; VARELA, Francisco J.. A árvore do conhecimento: as bases biológicas da compreensão humana. São Paulo: Palas Athena, 2003.

MONTANGERO, J.; MAURICE-NAVILLE, D. Piaget ou a inteligência em evolução, Porto Alegre: ARTMED, 1998.

MOORE, Michael; KEARSLEY, Greg. Educação a distância: uma visão integrada. São Paulo: Thomson, 2007.

PIAGET, J. Estudos sociológicos, Rio de Janeiro: Forense, 1973 